\title{
Cotidianidad, dinamismo y espontaneidad en la religiosidad popular: el fenómeno de los rosarios públicos en la Sevilla del Barroco
}

\author{
Carlos josé Romero Mensaque *
}

\begin{abstract}
RESUMEN
Este artículo estudia el fenómeno de los Rosarios públicos en la ciudad de

Sevilla durante los años finales del siglo xvil y todo el xvIII. Tras una breve

introducción sobre la génesis de la devoción del Rosario en la ciudad, centrada especialmente en su momento álgido de la segunda mitad del XVII, se analizan los antecedentes inmediatos de los Rosarios, las primeras procesiones espontáneas y se detalla todo el proceso de conformación del cortejo: cruces, faroles y Simpecados. Posteriormente se establecen los distintos tipos de procesiones: ordinarias (prima noche $y$ madrugada) y extraordinarias (Gala,

Penitenciales, Ánimas...), la participación de mujeres y niños en un uso que se quiso exclusivo por el clero sólo para varones. Para finalizar, dos cuestiones claves sobre el Rosario: la importancia del barrio como
\end{abstract}

\section{ABSTRACT}

This article deals with the phenomenon of telling "rosarybeads" in Seville during the later xvII century and the xvil century. After a brief introduction about the origin of the "rosarybeads" devotion in the city, mainly focussed on its nighest moment in the second half of the XVII century, the previous background of beads and its first procession are analized. All the structure of this procession is also given in detail: crosses, lanterns, and Simpecados. Then, the different kinds of procession are established: ordinary (early evening and dawn) and extraordinary (Gala, Penitenciales, Ánimas...), as well as the participation of womwn and children in a tradition which had been exclusively designed for men by the clergy. To conclude there are two key issues about beads: the importance of the suburb as the protagonistn of a

* UNED. Centro Asociado de Sevilla. 
protagonista de una religiosidad espontánea, dinámica y cotidiana y el papel de la hermandad como configuradora definitiva del uso rosariano. El artículo concluye con los signos de decadencia del uso devocional a fines del siglo xvili. spontaneous, dynamic and daily religiosity and the role of the fraternity as the definite ground where the beads use should be established. The article ends up with the signs of the decay of this traditional use by the end of the XVIII century.

La devoción del Santo Rosario constituye en Sevilla un paradigma de la religiosidad popular del Barroco a través de una de sus expresiones o uso más genuinas como el de los denominados Rosarios públicos o callejeros, que surgen a finales del siglo XVII, pero que suponen el último eslabón de todo un interesante proceso histórico, en que la devoción rosariana fue tomando carta de naturaleza en la ciudad como conformadora de todo un esquema socio-religioso en el que el pueblo se siente, quizá por vez primera, protagonista de la vida cotidiana de su ciudad como agente plenamente activo.

\section{ANTECEDENTES: GÉNESIS Y PRIMER DESARROLLO DE LA DEVOCIÓN DEL ROSARIO EN SEVILLA}

\section{a) El Rosario y la Orden de Predicadores. Cofradias. El Rosario en Sevilla}

Los orígenes del Rosario en Sevilla hay que vincularlos en principio a los conventos de la Orden de Santo Domingo (dominicos) donde desde 1479 se instituyen las denominadas Cofradías del Rosario, corporaciones dependientes de la Orden dedicadas al ejercicio de esta oración y culto a la Virgen. En este año, el Papa Sixto IV confirmó las constituciones de la primera Cofradía de la que se tiene noticia, que es la de Colonia ${ }^{`}$. Todo parece indicar que en el real convento de San Pablo se funda una de estas cofradías en fecha muy temprana, 1481, siendo Prior Fray Alonso de Ojeda, aunque la documentación propia más antigua que se conserva es de finales del siglo XVI ${ }^{2}$. Por estas fechas, la oración del Rosario se hallaba

\footnotetext{
Al parecer la Coiradia de Colonia se habia establecido ya en 1474 bajo la influencia del padre Alano de la Roche, fallecido un año después. Sobre los orígenes de la devoción, vid. ALONSO Getino, Luis, O.P., Origen del Rosario y leyendas castellanas del siglo XIII sobre Santo Domingo de Guzmán. Madrid, 1925.

2 El dato textual pertenece al Manuscrito de Fray Francisco Ramírez de Solórzano: Historia del Santo y Real Convento de San Pablo de Sevilla, de la Orden del Glorioso Patriarca Santo
} 
prácticamente conformada tal y como hoy la conocemos, tras una larga evolución en sus elementos a partir de las sencillas recitaciones de las avemarías que se detectan ya en el siglo XIII y que muchos autores asocian con la figura de Santo Domingo de Guzmán. De lo que no cabe duda es de que fueron los dominicos sus principales impulsores, especialmente, ya en la segunda mitad del siglo xv, Alano de la Roche, a quien se atribuye la propagación definitiva de este rezo y la iniciativa ya mencionada de las Cofradías del Rosario.

No obstante, la difusión de la devoción avemariana no adquirirá un carácter general hasta la segunda mitad del siglo XvI, especialmente a raíz de la Batalla Naval de Lepanto (1571), en donde la gran victoria de la Armada cristiana sobre el Turco fue, al parecer, atribuida a la milagrosa intervención de la Virgen del Rosario y a la coincidencia de que el mismo día la Cofradía establecida en Roma había salido públicamente por las calles practicando esta oración. El hecho fue que en 1573 el Papa Gregorio Xill expidió un Breve estableciendo el primer domingo de octubre como festividad de la Virgen del Rosario, a celebrar en aquellos lugares donde hubiera altar o capilla dedicada a esta advocación. La festividad se hizo general para toda la Iglesia española en 1671. En Sevilla se erige otra Cofradía dominica en el convento de Regina Angelorum (1589) ${ }^{3}$ y posiblemente diez años después una hermandad en la parroquia de San Marcos, la actual de San Julián, aunque no está documentada claramente su existencia hasta $1694^{4}$. Se constata un aumento de cofrades en las

Domingo... que se halla en los fondos documentales del Convento de Santo Tomás de Sevilla. Fol. 40 vto.. Es corroborado por varias fuentes: SAGREDO, J., O.P., La Hermandad del Rosario del convento de Regina Angelorum del Orden de Predicadores y la Real Maestranza de Caballería. Sevilla, 1923, pág. 13. En el Archivo de la Hermandad Sacramental de la Magdalena se encuentran diversos libros de la Cofradía del Rosario de San Pablo, entre ellos, un Expediente incompleto fechado en 1585 del pleito por el título rosariano sostenido con la Hermandad de la Oración en el Huerto. En los últimos folios afirma: “[...] con lo que mi parte es ya alegado y probado en ei proceso, de que resulta que la Cofradía de mi parte (Rosario) ha más de cien años que está fundada y erigida en esta ciudad con autoridad y aprobación de la Santa Sede Apostólica y del Rvdmo. General de la Orden de Santo Domingo [...]". Sobre la historia de esta Cofradía del Rosario, vid. mi artículo: "El Rosario y la religiosidad "oficial" en la Sevilla del Barroco: La Primitiva Cofradía del Rosario en el siglo XVIil", en Las fiestas de Sevilla en el siglo XV. Otros estudios. Madrid, CEIRA, 1991, págs. 233-249.

3 SagRedo, J, op. cit., pág. 13.

4 En el Archivo de esta Hermandad se conservan las Reglas de 1937, en cuyo prólogo se insertan unas memorias históricas a cargo de Eduardo Medio y Mármol en la que afirma la existencia de una Real Cédula del Consejo de Castilla por la que en 1599 son aprobados los estatutos de una corporación dedicada a la Virgen del Rosario y que contaba con el patronato de Felipe III e igualmente da noticia de una lápida en la que se hacia constar que el Conde de Castellar obtuvo en 1568 un Privilegio apostólico para el altar de la Virgen del Rosario de San Marcos. El documento más antiguo que he hallado es una copia de las Reglas de 1694 insertas en un expediente 
nóminas de la de San Pablo en la primera mitad del siglo XVI, pero no existía un arraigo popular de la devoción, ya que estas entidades eran un tanto elitistas, con una presencia evidente de la nobleza. Según Ortiz de Zúñiga, en los años finales del XVI o primeros del XVII había ya una cierta tradición de rezar el rosario en común todas las noches en los templos, junto con ejercicios de oración y penitencia, que comenzó en el Salvador y hospital del Amor de Dios y se generalizó en otros varios, incluso con la creación de hermandades 5 . En Córdoba sabemos que, bajo el influjo de su obispo, fray Martín de Córdova y Mendoza (1578-1581), se estableció en todas las parroquias de la diócesis la cofradía del Santo Rosario ${ }^{6}$.

Hay que insertar esta festividad del Rosario en los esquemas reformadores de Trento, potenciándose en lo pastoral una religiosidad efectista, plena de sensibilidad externa, de aparato festivo, signo de esa Iglesia "triunfante" frente al cisma luterano. La devoción es fomentada en Sevilla durante este tiempo por los arzobispos Agustín de Spínola en 1646 y, sobre todo, el dominico fray Pedro de Tapia en 1653 quien a[...] logró excitar grandemente y que se introdujese más frecuentemente el uso de rezar el Rosario en público en los templos, que ya antes más tibiamente se usaba" 7 . También en 1655 se promulga un edicto real de Felipe IV por el que hace un llamamiento a los obispos para la promoción de esta práctica devocional en sus respectivas diócesis. El Rosario se había convertido en un uso un tanto propagandístico de la Contrarreforma.

\section{b) La Peste de 1649 y las Misiones. El padre Ulloa}

Pero la verdadera carta de naturaleza del Rosario como devoción popular tiene efecto en la segunda mitad de esta centuria y a raíz del triste acontecimiento de la Pestilencia de 1649, verdadera catástrofe para los

posterior remitido al Consejo de Castilla en 1791 y en la que figura como una hermandad diocesana que se reactiva bajo el influjo de los Rosarios públicos. Cfr. Archivo Histórico Nacional (AHN), Consejos, leg 1661 , doc. 36 .

5 Ortiz de Zúniga, Diego, Anales eclesiásticos y seculares... de Sevilla. Año 1587 (3). Madrid, 1796. (Reed. facsímil de1988). Todo parece indicar que serían pequeñas congregaciones de actividad interna y no populares.

6 Moreno Valero, Manuel, “Religiosidad popular en Córdoba en el siglo XVili (Cofradía del Santo Rosario", Boletín de la Real Academia de Córdoba de Ciencias, Bellas Artes y Nobles Letras, núm. 112 (1987), pp 95-111. Interesantísimo estudio sobre la devoción del Rosario en Córdoba, haciendo muchas referencias a los rosarios públicos. Moreno afirma que, aunque se fundaran tantas cofradias, la devoción fue disminuyendo hasta que en los años finales volvió a revitalizarse a iniciativa del propio pueblo.

Cfr. ORTIZ de ZuÑIGa, Diego, op. cit., año 1653 (3). 
sevillanos, pues más de la mitad de la población pereció en medio de una gran conmoción. En un régimen de cristiandad como el que vivía Sevilla en el Barroco, el pueblo experimentaba un angustioso sentimiento de culpa, de pecado colectivo por el que Dios castigaba a la ciudad. Era precisa una conversión radical de vida a través del arrepentimiento y la penitencia. En tal sentido, la Jerarquía eclesiástica fomentó en las cuaresmas de los años subsiguientes sendas Misiones populares dirigidas por acreditados predicadores de las principales órdenes regulares. Toda Sevilla se congregaba para asistir a los distintos ejercicios misionales, creándose un clima de exacerbado dramatismo en torno a la religión.

El rezo del Santo Rosario se hace insustituible en estas Misiones. Especial mención hay que hacer a las que, promovidas por el arzobispo Ambrosio Ignacio de Spínola, dirigió el jesuita Tirso González de Santalla junto a sus colaboradores los padres Gamboa, Guillén y Losada, los años 1669,1672 y 1679. Era este sacerdote especialmente afecto a esta devoción, que fomentaba en todos los ejercicios de la Misión. Se constata que en el acto público de contrición, gran cantidad de personas procesionaban rezando y cantando diversas coplas tras el Crucifijo con cruces, velas y rosarios en las manos. Igualmente todos los días se practicaba en las iglesias el Rosario a coros e hizo imprimir folletos breves sobre el modo de rezar el Rosario.

A fin de preservar que el clima penitencial creado en las misiones no se entibiara y los fieles pudieran perseverar en las prácticas propuestas en las predicaciones, el padre Tirso fomentó la creación de varias hermandades de culto interno dedicadas a ejercicios de penitencia y el rezo del Santo Rosario, concretamente las denominadas congregaciones de Cristo Crucificado y Nuestra Señora del Rosario que se erigieron por varios devotos en las parroquias del Divino Salvador, San Vicente, San Pedro, San Bartolomé, San Esteban y quizá otras como la de Santa Ana. Aunque tuvieron cierto arraigo entre las feligresías, no fueron entidades de hondo calado en las capas más populares de la población. Sin embargo es significativo como comienza a quebrarse el monopolio dominico sobre las corporaciones rosarianas.

Se daba una progresiva identificación entre la devoción rosariana y esa religiosidad que se iba configurando en las Misiones: el acercamiento sentimental a los Misterios de la vida de Cristo, la dramática llamada a la conversión desde una vida ociosa y efímera basada en lo material hasta otra más espiritual y eterna, la práctica de las virtudes, recepción de los sacramentos, todo ello que creaba una atmósfera casi ideal de santidad en que como decía el propio Tirso: Con esto ha quedado la ciudad de Sevilla hecha un cielo... El encuentro con Cristo a través de la dulce mediación de 
la Virgen María en el rezo del Santo Rosario supone para gran parte del pueblo una forma sencilla, entrañable y directa de "sacramento", incluso más allá de los propios sacramentos de la Iglesia. Esto se hará patente con las predicaciones del padre Ulioa ${ }^{8}$.

Y llega la hora de los dominicos. Tras el difícil trance de la «cuestión concepcionista" a comienzos de siglo en que vino a ponerse en entredicho su marianismo, se convirtieron en los adalides de la devoción rosariana gracias a la personalidad carismática de fray Pedro de Santa María de Ulloa, llamado "el apóstol del Rosario», que desde su convento de San Pablo y durante tres años (1688-1690) provocó una auténtica catarsis colectiva en torno al rezo del Santo Rosario, al que convirtió en signo de identidad mariana para toda la ciudad y que, sin pretenderlo como tal, fue el motor de una religiosidad auténticamente original, espontánea en donde el pueblo llano se va a convertir quizá por vez primera en Sevilla en promotor y protagonista.

Habia adoptado el sistema de rezar todos los días comunitariamente el Rosario entero, es decir, los quince misterios, divididos en tercios, que se desarrollaban al amanecer, mediodía y al toque de oraciones. Previamente a cada tercio, dirigía una plática considerando los misterios que se iban a meditar. Una muestra de estas meditaciones se hallan en su libro "Arco iris de paz". En un primer momento, estas predicaciones y rezos se celebraron en la capilla de la Virgen de la Antigua, un lugar de tradición rosariana desde la época de la Peste, pero pronto, ante el gran concurso de fieles, hubieron de trasladarse a la iglesia. Ulloa supo captar perfectamente las inquietudes de los fieles y trató de encauzar su religiosidad en torno al Rosario, aunque algunas de sus expresiones, llevadas sin duda por la emotividad y el fervor de su celo apostólico, fueron

\footnotetext{
8 Sobre las Misiones del P. Tirso González, el estudio más detallado es el de Elías Reyero: Misiones del P. Tirso González (1665-1686). Santiago de Compostela, 1913. En él se recogen literalmente las memorias del religioso sobre estas Misiones. Se puede constatar que los misioneros jesuitas promovieron la fundación de estas congregaciones y hermandades en sendas predicaciones celebradas en estas parroquias. La del Salvador data de 1669 y las restantes tuvieron efecto durante las Misiones de 1672 y 79 con sus mismos estatutos (salvo la de Santa Ana). En las primeras Reglas de la Hermandad de San Vicente (1691) se explicitan estos origenes. (Cfr. Archivo Hermandad de las 7 Palabras). En San Esteban es constante que a partir de 1670 vecinos y devotos de la Virgen de la Luz se reúnen todas las noches a rezar el Rosario y siete años des. pués erigen una hermandad. El propio Tirso refiere que los padres Guillén y Gamboa fundaron una congregación que bien pudo ser el origen de la Hermandad de Nuestra Señora de la Alegría (Cfr. op. cit. pág. 318). En 1672 se aprueban los estatutos de la Congregación de Cristo Crucificado y Nuestra Señora de Consolación y Rosario de la parroquia de San Pedro (Cfr. Archivo Palacio Arzobispal (A.P.A.), Hermandades., leg. 58). En las primeras Reglas de la Hermandad de Santa Ana y Devoción del Santo Rosario se menciona a los misioneros jesuitas como promotores de la misma en 1679. (Cfr. Archivo Hermandad Madre de Dios del Rosario. 1693).
} 
criticadas por diversos sectores eclesiásticos de la ciudad por parecer que absolutizaba el Rosario como medio eficaz de Salvación, en detrimento incluso de los sacramentos. Como queda dicho, pudo haber algo de esto, aunque no lo pretendiera Ulloa, como tampoco nunca pudo prever el alcance de sus predicaciones. Su muerte causó un impacto tremendo en toda Sevilla y durante muchos días fueron muchos los que se acercaron a velar su cadáver y conseguir de cualquier manera alguna reliquia de quien consideraban un santo ${ }^{9}$.

Se atribuye tradicionalmente a este fraile el influjo definitivo de la «explosión rosariana" con la salida de los primeros Rosarios públicos, espontánea iniciativa que tuvo efecto por vez primera la noche del 17 de junio de 1690, fecha en que se celebraron en el real convento de San Pablo los solemnes funerales por su alma. Unos devotos cofrades de San Bartolomé pertenecientes a la Hermandad de Nuestra Señora de la Alegría salieron comunitariamente en procesión por las calles rezando el Santo Rosario y cantando coplas marianas. Era el comienzo de este gran movimiento popular ${ }^{10}$.

\section{LOS ROSARIOS PÚBLICOS}

El Rosario público se manifiesta como la expresión genuina de la devoción rosariana en Sevilla desde fines del siglo XVII hasta la segunda mitad del XIX e incluso con reminiscencias posteriores.

Junto a aquellos cofrades de la Virgen de la Alegría, un creciente número de feligreses de la mayoría de las parroquias, iglesias y conventos asi como hermanos de otras hermandades organizaron sendos rosarios

9 Sobre la figura y obra apostólica del padre Ulloa, vid AAANDA, Gabriel de, S.I., Vida del siervo de Dios, exemplar de sacerdotes el venerable padre Fernando de Contreras. Sevilla, 1692 , págs. 891-896. Igualmente se puede consultar el prólogo de la obra autógrafa de este fraile Arco iris de paz. Barcelona, 1765 y que redactó fray Diego de la Llana. Sobre las controversias acerca del tenor de sus predicaciones, vid. mi artículo: «El fenómeno rosariano como expresión de religiosidad popular en la Sevilla del Barroco", en La Religiosidad popular, Actas del I Encuentro de Religiosidad Popular de la Fundación Machado. 3 tomos. Barcelona, Anthropos, 1989, vol 2., págs. 540-553.

10 ORTIZ DE ZÚNIGA, Diego, op. cit. Año 1690 (9). (Adiciones Espinosa y Cárcel). El analista afirma que fue la primera procesión de Rosario público, con cruz y Simpecado, recogiendo el testimonio de varios autores que no cita. En las Reglas de la propia Hermandad de 1731 se atestigua esta primacía que extiende incluso a toda España. Tan celosa ha sido de este privilegio que en acta capitular de 20-6-1738 acuerda declinar la invitación del Rosario de Santo Tomás para asistir a la colocación del nuevo Simpecado del Rosario de la Virgen de la Antigua en las Gradas, por no admitirsele un lugar de primacía entre todos los rosarios de la ciudad que acudieran. 
que inundaron las calles de la ciudad, número que progresivamente fue en aumento durante los años finales del siglo y primera mitad de la centuria siguiente. El propio arzobispo Palafox fue un decidido impulsor de este uso. Aunque se instituyeron la mayoría en templos y, por tanto, bajo la coordinación o supervisión del clero secular o regular, igualmente se generalizaron extramuros al ser erigidos también por los propios vecinos de los barrios en torno a retablos callejeros con una imagen de la Virgen representada en un lienzo o talla, que en muchos casos eran construidos por ellos mismos o bajo sus expensas. Estos retablos se constituían en los puntos de salida de la comitiva procesional ${ }^{11}$.

\section{a) Los primeros Rosarios: trasunto popular de las Misiones}

En un primer momento salian estas comitivas o "cuadrillas" sin ningún tipo de insignias o imágenes salvo los faroles para alumbrar el camino y a los devotos, cantando alabanzas y coplas a la Virgen y dirigidos por uno o dos eclesiásticos que controlaran el orden de la comitiva, marcaran el itinerario y paradas e hicieran los ofrecimientos de los Misterios. A ello no obsta que algunos sacaran desde el primer momento algún estandarte o Simpecado mariano, pero no de manera organizada ni individualizando el cortejo. Estos primeros rosarios eran muy espontáneos y podemos definirlos como auténticos trasuntos de aquellos rezos comunitarios que dirigía Ulloa en el convento de San Pablo. En un impreso del mismo año $1690^{12}$ se describe la composición y desarrollo de uno de estos rosarios una vez que, rezados los misterios gozosos en la iglesia, se sale a la calle para continuar los otros dos:

«Propone un señor sacerdote el primero Misterio que ha de meditar (habiendo precedido el acto de contrición) dicen el paternoster y diez avemarías

\footnotetext{
11 Justino Matute y Gaviria nos suministra la relación de los primeros rosarios públicos: Hermandad de la Cruz del Rodeo, parroquia de San Julián, iglesia de San Esteban, parroquia del Sagrario, colegial del Salvador, parroquias de S. Juan de la Palma, S. Vicente, S. Andrés, S. Gil, Santa Catalina, S.Román, S. Martín, S. Pedro, Santiago, S.Nicolás, S. Marcos, Santa Ana, S. Isidoro, Santa Cruz, Hermandad de los Negritos, parroquias de S. Roque, S. Miguel, Santa Lucía, S. Lorenzo, Omnium Sanctorum, S. Bernardo, Convento de S. Jacinto, Hermandad de la O, parroquias de la Magdalena, S. Ildeionso, Santa Marina, Santa María la Blanca y, por supuesto, el convento de San Pablo, aunque de estos tres últimos no se especifica fecha de salida. Cir. Anales eclesiásticos y seculares..., Sevilla, 1887. Hay una nueva edición facsímil de 1997. Antonio Hernández Parrales afirma que la procesión de San Esteban fue organizada por los cofrades de la Virgen de la Luz con estandarte y faroles. (Cfr. La iglesia de San Esteban. Sevilla, 1975, págs. 24-26.

12 Noticia que exhorta todos cuantos la alcanzaren a que imiten la devoción y forma con que se reza en la Muy Noble...ciudad de Sevilla el Santísimo Rosario de la Reina de los Ángeles, Maria Virgen y Madre de Dios... Sevilla, 1690.
} 
y el gloria patri, se paran todos, y ofrece el dicho señor sacerdote el dicho Misterio por el ordinario librito de Ofrecimientos del Rosario y consecutivamente dice las alabanzas que compuso el venerable padre (Ulloa) que son las siguientes: diez mil veces sobre centenares de millones de veces sea bendita, alabada, glorificada, predicada y ensalzada la inefable, beatísima y santísima Trinidad Padre, Hijo y Espíritu Santo, Tres Personas y un sólo Dios, de Sí mismo, de la santísima humanidad del Señor, de la bienaventu. rada y gloriosa siempre Virgen María, concebida en justicia y gracia original en el primero instante de su ser, de toda la corte triunfante y militante y de todas las criaturas, de todo nuestro corazón, vida y alma, con todas nuestras fuerzas, potencias y sentidos en sí mismo, en la sacratísima humanidad del Señor, en la bienaventurada y gloriosa siempre Virgen María, en todos los ángeles y bienaventurados aora y por siempre y por los siglos infinitos de los siglos" $Y$ responden todos: amén. $Y$ prosigue el sacerdote: Bienaventuradas las entrañas purísimas de María Santísima que por tiempo de nueve meses encerraron al Hijo de Dios. Y dicen todos: amén. $Y$ el sacerdote: Bienaventurados aquellos santísimos y virginales pechos que le dieron leche. $Y$ repiten todos: amén. $Y$ esto se repite en todos los dieces con advertencia que al segundo se dice: veinte mil veces, al tercero: treinta y asi se prosigue, aumentando diez a diez avemarías hasta el último diez de los tres tercios, que se acaba con ciento y cincuenta mil veces."

El rosario reproducía aquel clima de fervor y entusiasmo que creaba Ulloa en sus predicaciones, pero con tres características originales: la espontaneidad del pueblo con la coordinación de sus sacerdotes, el dinamismo que rompe el ámbito templario y va hacia el entorno vital de las gentes y la cotidianidad. La duración de estas primeras estaciones solía ser de unas dos horas, con un ritmo más bien lento en los cantos de las avemarias. Al igual que ocurría en las iglesias, el rosario era cantado a coros. Así lo explica este impreso:

«Y para evitar la confusión de voces, no siendo todos iguales en la pronunciación pues unos acaban más presto que otros, rezan los coros en esta forma: la mitad del paternoster y avemarías las cantan tres o cuatro voces, que se escogen de las mejores y las restantes todos juntos y al otro diez se alternan empezando todos y prosiguiendo los cuatro que siempre van en medio, para que todos los oigan y acaben diciendo las letanías de Nuestra Señora y la Salve con la oración».

En estos primeros rosarios ya se advierte que la participación es exclusivamente masculina, normalmente de jóvenes y adultos, aunque también van niños

"crece en tanto el número que ha habido cuadrilla a quien la curiosidad le contó más de mil y quinientas personas entre hombres y niños y de estos van muy muchos que aún no tienen cuattro años, a quienes habiendo querido evitar el que se fuesen por el cansancio que amenazaba a su delicada 
pequeñez, se deshacian en llantos hasta que los volvían a introducir en las cuadrillas, admirando a todos la constancia con que andan estación tan desproporcionada a tan débiles fuerzas y la puntualidad con que la noche siguiente son los primeros que acuden a las iglesias, causando en los hombres (además del ejemplo que nos dan) espiritual fruición al ver que saludan a María Santísima tantos ángeles humanos".

El Rosario se plantea como un ejercicio de devoción y piedad, pero a la vez ostenta un claro carácter penitencial derivado del clima de las Misiones, mas, como queda dicho, con una religiosidad conformada por el pueblo que se hace dinámica y cotidiana a través de un esquema estético y sensible con el rezo de las avemarías y el canto de coplas alusivas a María. Es un signo inequívoco de la cristiandad barroca, que se asume como algo connatural a la propia idiosincrasia del pueblo.

Ciertamente el Rosario público, aunque surge de manera espontánea en 1690 , tiene unos claros precedentes durante el siglo XVI en las ya nombradas cofradías del Rosario dominicas que celebraban los primeros domingos de mes procesiones claustrales con la imagen titular con asistencia de los cofrades con rosarios en las manos y otra solemne por la calle en la festividad del primer domingo de octubre (Procesión de la Batalla Naval). Igualmente en las Misiones populares se organizaba una multitudinaria procesión en la que, en pos de un Crucifijo portado por los misioneros, iban las gentes rezando con rosarios y cruces en las manos y además se fomentaba entre los niños el ir por las calles cantando a coros coplas religiosas ${ }^{13}$. El marianismo de la ciudad desde la cuestión concepcionista hubo de hacer esto mucho más claro y muchos elementos: simpecados, coplas...se van incorporando a las expresiones de piedad mariana del pueblo. No obstante, el rezo comunitario como tal por las calles, lo que es propiamente un Rosario público, con sus insignias y faroles, no aparece claramente en Sevilla hasta ahora.

En Andalucia el fenómeno está poco investigado como tal, salvo en Córdoba, donde es coetáneo a Sevilla. En Granada, Jaén o Málaga parecen seguir también los mismos esquemas que he observado en Sevilla y durante el siglo XVIII ${ }^{14}$. En Cádiz nos encontramos con la carismática

13 Esto ya aparece, por ejemplo, en las Misiones del jesuita, padre León que él mismo narra (1578-1616). Cfr. Grandeza y miseria en Andalucia. Testimonio de una encrucijada histórica. Granada, 1981, pág. 179. Se refiere concretamente a los chicos que iban cantando por las calles coplitas devotas. Las procesiones multitudinarias rezando con los rosarios en las manos aparecen en las Misiones del P. Tirso. Vid. REYERO, op. cit. , pág. 189.

14 Vid., por ejemplo, LóPEz MuÑoz, Miguel Luis, "Implantación de las cofradias en la diócesis de Granada durante la Edad Moderna" o CORONAS TEJADA, Luis: "Manifestaciones de la religiosidad popular en Jaén durante la Edad Moderna", ambos en Congreso de Religiosidad Popular en 
figura del capuchino fray Pablo, al que me refiero a continuación. En otras zonas de España, existen pocos estudios al respecto.

\section{b) Orden y composición definitiva de los cortejos. El Rosario como reactivador de la pastoral parroquial y de la vida de las hermandades}

Pronto se configuró la estética externa de estos Rosarios con la inclusión de la que será su insignia más distintiva, el Simpecado, que singularizaba cada comitiva. Sólo desde entonces pueden considerarse ya institucionalizados. Es sintomático que, aunque la Hermandad de la Luz de San Esteban sacara su primer Rosario en 1690, muy poco después del de la Alegría, sus cofrades no consideran erigida esta procesión hasta 1711, en que se adquiere el Simpecado y se nombra una diputación especial para su gobierno ${ }^{15}$. Este Simpecado, estandarte bordado en oro o plata con un lienzo central representando una imagen de la Virgen, se halla relacionado con la "cuestión concepcionista" ${ }^{16}$ y era un signo de identidad mariano. El color más característico de estos Simpecados es el rojo carmesí, aunque se constatan también el blanco, verde, celeste, morado o negro, según el carácter de la propia institución que lo organiza o si se trata de un Rosario de ánimas o penitencial. Junto al Simpecado, pronto aparece la cruz como insignia que precede la comitiva ${ }^{17}$. Igualmente

Andalucia. Cabra, Cajasur, 1994, págs. 101-140. y 141-150 respectivamente. En Córdoba, el artículo cit. de Moreno Valero. En Málaga se está iniciando una tesis sobre este fenómeno dirigida por la doctora Marion Reder Gadow.

15 Archivo Hermandad de $N^{a} S^{a}$ de la Luz, Libro de cargo y data, 1711, cabildo de rendición de cuentas de 31-12-1711.

16 Entre 1613 y 1617 Sevilla vivió intensamente una sonora controversia acerca de la entonces "opinión piadosa" de la Inmaculada Concepción de la Virgen, que defendían los franciscanos frente a los dominicos. Estos últimos cometieron la grave imprudencia de expresar en público sus argumentos negativos sobre este priviliegio de María, lo que provocó, dado el secular marianismo de las gentes, una auténtica "explosión concepcionista" en la que el pueblo se lanzó literalmemte a la calle, aleccionado ciertamente por franciscanos y jesuitas, celebrándose muchas procesiones multitudinarias "de desagravio" a la Virgen. Una comisión sevillana presidida por Mateo Vázquez de Leca se trasladó a Roma para solicitar del Papa algún documento explícito sobre este tema, to que tuvo efecto en 1617 con un Breve muy favorable, que obliga prácticamente al silencio a quienes sostuvieran tesis negativas frente a la Concepción Inmaculada. Vid. sobre esta cuestión, sobre todo: Serrano Ortega, Manuel, Glorias religiosas de Sevilla. Noticia histórica de la devoción y culto que la MN y ML ciudad de Sevilla ha profesado a la Inmaculada Concepción. Sevilla, 1893.

17 He constatado un Simpecado de color blanco y ramos de oro en el Rosario de San Marcos a finales dei siglo XVIII. Cfr. en un inventario inserto en largo expediente al Consejo de Castilla solicitando que por estar recogidas las Reglas de la corporación, tras sufrir decadencia, se le permita convocar cabildo para aprobar un nuevo proyecto de Reglas a fin de que no se extinga la Hermandad. Cfr. Archivo Palacio Arzobispal (A.P.A.). Hermandades, leg. 23. La Hermandad del 
tiende a cuidarse más el acompañamiento musical tanto en los coros como en el añadido de auténticas orquestas. Todo esto hace que la comitiva fuera complicándose con un gran aparato externo, se perdiera la primitiva espontaneidad y se necesitara un continuo desembolso económico para su mantenimiento diario.

En esta conformación de la comitiva rosariana van a influir de manera decisiva los religiosos capuchinos, que la promueven sistemáticamente en todas sus Misiones. Hay que referirse en especial a fray Pablo de Cádiz, otro auténtico "apóstol del Rosario" y al que su hermano de religión, fray Isidoro de Sevilla, atribuye la institución formal definitiva de los Rosarios públicos, introduciendo al principio una cruz, a la que seguirían los faroles de asta y de mano alumbrando los coros y, sobre todo, un estandarte mariano, que cerraba y presidia la comitiva, saliendo por vez primera la procesión conformada en siete de febrero de 1691 por las calles de Cádiz ${ }^{18}$.

Es bastante probable que en Sevilla ya existiera este modelo (Espinosa y Cárcel afirma en los Anales que en 1690 estaba ya instituido), aunque quizá de manera un tanto informal y en estas procesiones se inspirara el capuchino. Igualmente refiere que los cofrades de la Alegría ya salieron con luces e insignias... Lo cierto es que la Orden Capuchina trató de encauzar esta práctica junto con dominicos, jesuitas y otras órdenes y, por supuesto, el clero secular. Se conservan diversas publicaciones o manuales prácticos sobre la organización normativa de estos rosarios ${ }^{19}$.

Rosario de la Resolana poseía un antiguo Simpecado de color verde, como aparece en un Inventario inserto en expediente gubernativo con fecha de 30-5-1759. No se sabe si lo sacaba en los Rosarios o quizá perteneciera a la antigua hermandad de la Santa Cruz. Cfr. Archivo Palacio Arzobispal (A.P.A.) Hermandades, leg 211. El simpecado celeste es propio de los rosarios cuya titular la Inmaculada, por ejemplo el de los Cuatro Cantillos de Santa Marina. También lo era el de $\mathrm{N}^{\mathrm{a}} \mathrm{S}^{\mathrm{a}}$ de la Antigua (Gradas). El morado, propio de los Rosarios de Ánimas se documenta también en el citado legajo 211. El negro parece propio de las penitenciales, como se observa en el caso del Rosario de la parroquia de San Pedro.

18 Sobre este religioso, vid. IsidORO dE SEVILLA, La nube de Occidente. Vida y virtudes de... fray Pablo de Cádiz. Cádiz, 1702, que cita Palomero Paramo, Jesús M. en "Entre el claustro y el compás: el esplendor de las órdenes religiosas", en Catálogo Magna Hispalensis: el universo de una Iglesia, Sevilla, 1992, pág. 220, en que suministra una breve, pero interesante sintesis de la devoción rosariana. Fray Pablo llegó a erigir 31 rosarios públicos antes de su fallecimiento en 1694. Fray Isidoro continuó esta labor en Sevilla, uniéndola a una nueva y carismática devoción que él mismo crea: la Divina Pastora de las Almas.

19 El propio fray Pablo escribió Triunfo glorioso del Santísimo Rosario que era un manual sobre este uso, avalado por el propio obispo de Cádiz José de Barcia y Zambrana. Son interesantes igualmente las obras de los también capuchinos fray Pedro José DE SEVILLA, Gritos del capuchino enfermo. Sevilla, 1724 y Antonio IRIBARRE, Práctica del Santísimo Rosario, con el universal concurso de los católicos pueblos, cantándolo por las principales plazas y calles, con un despertador de la conciencia... Madrid, 1697. 
En las primeras décadas del siglo xvIII está ya perfectamente establecido el orden y composición de estos rosarios. A continuación, transcribo el tenor del capítulo que sobre este tema recogen las Reglas de una hermandad rosariana, la de la Santa Cruz y Nuestra Señora del Rosario de la Resolana, que surge a fines del siglo xVII al amparo de una congregación de la Santa Cruz que radicaba en una capilla-humilladero y es un ejemplo claro de la autonomía a que habían llegado los rosarios respecto a la tutela clerical, pues es el Hermano Mayor el principal responsable de la procesión ${ }^{20}$.

"(Cap. 11 De la forma que se a de executar las estasiones de mañana y noche para su mexor govierno=En las estaziones de todos los dias que queda asignado en el capitulo precedente para la madrugada y prima, conviene se proseda con prudente govierno para durasión y permanencia para cuia razón cuidará el Hermano Mayor que la campanilla que sale antes por las calles llamando a los hermanos y devotos no se conseda a muchacho ni hombre que cauze alvoroto o excándalo sino la dará a persona de razón que executará el llamamiento conquistando si dará motivo a que algunos se quexaran ....al Hermano Mayor en caso que aiga muchos que quieran llevar la cruz o simpecado distribuia uno y otro procurando con buenas razones queden todos gustosos para que se consiga la paz, y el Prioste le toca repartir los faroles altos y vaxos y por quantas estaziones que se suelen asignar por acuerdo para todos los dias se suelan ynvertir por justos motibos que después ocurren como son haver en ella obras o mucho lodos o haber de yr a cantar responso y salve en otros sitios diferentes declaramos que el señalamiento de estaziones toca al Hermano Primero privativamente y en su ausienzias a uno de los dos diputados y en la de ambos al Capellán y quando cada uno le toque señalarán la estazión al tiempo de salir el Rosario partisipándoselo al que llevare la cruz para que expesialmente la siga sin admitir orden en contra de otra persona alguna y se encarga que las estaziones sean moderadas para no causar al hermano o fatiga o cansanzio. Para governar el Rosario por las calles yrán en orden dos campanillas con esto desimos para quitar confuzión, una llevará el padre capellán que irá al prinzipio del Rosario ynmediato a la cruz y no la tocará sino quando encuentre otro Rosario y para lo que sea presiso: que el nuestro pare o para ofrezer y la otra llevará el Hermano Mayor que irá junto a los faroles altos y la tocará en saliendo del Rosario de la capilla siempre que vea en él alguna quiebra o ubiere de parar para cantar alguna salve o responso y ninguno desamparará su puesto si no fuera con gran motivo. $Y$ por quanto suele avisar para que el Rosario vaya a cantar responso a los difuntos o salve a los enfermos, establezemos para el admitir el convite y hazer que vaya el Rosario toca a el Hermano Mayor [...]".

20 Expediente de aprobación de Reglas. 1746. Archivo Palacio Arzobispal (A.P.A.), Hermandades, leg. 211. 
Los rosarios públicos suponen una reactivación muy importante de la pastoral parroquial respecto a la generalidad de la feligresía y asimismo de la vida de las hermandades y cofradías. En la cofradía antedicha, el Rosario consigue reorganizar una corporación, la de la Santa Cruz, prácticamente extinguida. En no pocos casos, se modifica el instituto, pasando el Rosario público a tener la preeminencia sobre el culto propiamente dicho a la imagen titular. Ejemplos no faltan de todo esto: hermandades de la Virgen de Europa de su retablo de las Pasaderas de San Martín, las hermandades de la Concepción de sus capillas-retablo de las Gradas de la Catedral, Cuatro Cantillos o Postigo del Aceite, Nuestra Señora de la Alegría, de la parroquia de San Bartolomé, Nuestra Señora del Coral de la parroquia de San Ildefonso, Nuestra señora de la Luz de San Esteban, la Virgen del Amparo de la Magdalena...

\section{c) Tipos de procesiones}

Prácticamente desde el principio se organizaron a diario dos procesiones de estos rosarios, una a prima noche, tras el toque de Oraciones y otra de madrugada, tras el toque de alba. Esta segunda procesión se denominaba también de la aurora por salir dos horas aproximadamente antes de salir el sol, a cuyo término los cofrades asistían a la denominada "misa de alba". Estas procesiones de madrugada serán las más comunes a partir del siglo XIX, adoptando definitivamente la denominación de Rosarios de aurora, coincidiendo con una iniciativa de su fomento a nivel nacional, a cargo del padre misionero Antonio Garcés, a fines del XVIII. En las fiestas organizadas por la Ciudad en conmemoración del Patronato de la Inmaculada sobre los reinos españoles, vinieron muchos rosarios públicos a la Catedral, entrando al toque de alba, que eran las tres de la mañana y allí cada corporación asistió a las misas que se celebraron para cada uno en las capillas ${ }^{21}$. Hubo rosarios en la primera época que, con el alba, se reunían para escuchar la primera misa de los templos y luego hacían la estación ${ }^{22}$. Era frecuente que una misma institución - parroquia, convento, hermandad o grupo de vecinos- organizara ambas procesiones, predominando el uso diario de la primera de prima noche, y reservando en ocasiones la segunda para los días festivos. Pero es difícil generalizar, pues cada comitiva actuaba con una gran autonomía.

21 Fiestas por la proclamación de la Inmaculada Concepción... Manuscrito de la Biblioteca Capitular. 80-1-88.

22 Vid. nota 10 
A mediados del siglo XVIII estaban contabilizados 81 rosarios de hombres y 47 de mujeres, aunque no sabemos si en este número figuran separados los de prima y madrugada, que organizaba una misma corporación. Ya queda dicho que cabe hablar de Rosarios templarios (parroquias, conventos, capillas) o extratemplarios. Si nos ceñimos exclusivamente a los radicados en retablos callejeros, el documentado libro de Fernández de Paz nos reseña los siguientes a mediados del siglo xvill: el de la Asunción en las Gradas de la Catedral, el de Nuestra Señora del Rosario en los Humeros, el de Nuestra Señora de la Merced en la Puerta Real, el de Nuestra Señora de la Rosa en el pórtico de los Clérigos Menores, el de Nuestra Señora de Europa en las Pasaderas de San Martín, el de Nuestra Señora de Belén, en la calle Gallegos, los de Nuestra Señora del Carmen, en calle Vizainos y San Alberto, los de la Concepción, en el Postigo del Aceite, Cuatro Cantillos y calle del ABC, el de Nuestra Señora de los Desamparados de calle Carpintería, el de Nuestra Señora de Regla, en calle Cerrajería, el de Nuestra Señora de Nieva, en la Puerta Osario, el de Nuestra Señora de la Soledad, en La Laguna, el de Nuestra Señora de Valvanera, en calle Chicharreros, el de Nuestra Señora de la Visitación, en la puerta de la Cárcel Real, el de Nuestra Señora de la Antigua en las Gradas de la Catedral y el del Cristo de la Expiración, bajo los portales de la plaza de San Francisco ${ }^{23}$.

Como se observa, el Rosario marcaba toda la vida religiosa de los barrios de la ciudad en una cotidianidad dinámica. Pero la procesión no era siempre la misma ni en sus aspectos formales ni en las estaciones que realizaba. Junto al Rosario de a diario, había varias ocasiones a lo largo del año en que la procesión adquiría un carácter extraordinario: así en las vísperas de la festividad de la Virgen titular se sacaba el denominado Rosario de Gala, denominado así porque contaba con unas insignias propias: cruces doradas con espejos, Simpecado con bordados y lienzo de gran calidad, faroles artísticos, orquestas profesionales y estaciones significativas. En varias hermandades se organizaban con este Rosario las "Novenas de calle», como ocurría por ejemplo en el de la parroquia de Santa Catalina, y que consistía en la salida procesional por las calles de la feligresía durante nueve días, los mismos en que se celebraba la Novena de iglesia ${ }^{24}$.

${ }^{23}$ Religiosidad popular sevillana a través de los retablos de culto callejero. Sevilla, 1987, pág. 125.

24 Sobre esta Hermandad durante el siglo XVIII, vid. mi artículo: "Hermandad, parroquia y religiosidad popular en Sevilla: La Hermandad del Rosario de Santa Catalina en el siglo xvilı, en Guía de los Archivos de las Cofradías de Semana Santa de Sevilla. Madrid, CEIRA, 1991, págs. 229-248. 
Otro Rosario extraordinario era el de Ánimas, que cada congregación organizaba durante nueve días (Novena de Ánimas) haciendo estación a retablos de ánimas, cruces o cementerios. Se ha podido constatar la utilización de un Simpecado morado o negro con un lienzo de dolor, como el que todavía conserva el Rosario de los Humeros ${ }^{25}$.

Otros tipos de procesiones extraordinarias ya son menos frecuentes: había, por ejemplo, Rosarios penitenciales que acudían los viernes de Cuaresma al Humilladero de la Cruz del Campo como el Rosario de la Fuensanta de San Pedro ${ }^{26}$, Rosarios de rogativas en ocasión de alguna calamidad pública, como los muchos que recorrieron a la ciudad cuando ocurrió la Peste de $1800^{27}$, Rosarios de Acción de Gracias, como los que salieron en conmemoración de la visita de Felipe $\mathrm{V}$ a la ciudad.

\section{d) Los rosarios de mujeres y de niños}

Las mujeres habían quedado relegadas de este uso devocional debido a las prevenciones propias de la época, sobre todo si, como ocurría con los Rosarios, se desarrollaban de noche y habian de conformarse con hacerlo en sus domicilios o bien, se juntaban algunas en coches rezándolo a coros y realizando diversas estaciones. No obstante la inquietud era latente y fue nuevamente un fraile dominico, fray Pedro Vázquez Tinoco, quien en 1735 promovió el primer Rosario de mujeres en la iglesia de Santa Cruz, al que siguieron en un primer momento veinticuatro más. Esta iniciativa suscitó una gran diversidad de opiniones en la ciudad y fueron muchos quienes la criticaron abiertamente 0 a través de letrillas burlescas amparadas en el anonimato. No faltaron tampoco decididos defensores. El uso perseveró y adquirió una notable expansión bien de manera autónoma, bien dependiendo de rosarios de hombres o de la entidad que los patrocinaba ${ }^{28}$. Por

25 Cfr. mi monografía editada por la Hermandad: El Rosario de los Humeros. Estudio histórico y patrimonial de la Hermandad de Nuestra Señora del Rosario y Santo Cristo de la Paz. Sevilla, 1993, pág. 56.

26 Congregación dedicada al instituto rosariano erigida en 1727 , que tuvo un enconado pleito con la comunidad franciscana de Villaverde, por la utilización del nombre de la Virgen para el Rosario, amén de reproducir su imagen en el Simpecado. Lo más curioso es que muchos cofrades de la hermandad de Aguas Santas de aquella localidad estaban inscritos en la congregación de San Pedro. En todo ello hay un conflicto jurisdiccional y, sobre todo, económico, pues disminuían las limosnas al convento. Cfr. Archivo Palacio Arzobispal (A.P.A.), Hermandades, leg. 58.

27 Matute y Gaviria, J.,op. cit. Año 1800 (12) Junto a muchas procesiones con imágenes de la Virgen, se menciona específicamente como Rosario al de Nuestra Señora de la Aurora de Santa Marina.

28 Ibidem. Año 1735 (6 y 8). El primer Rosario salió el 1 de noviembre. Los otros cortejos que le siguen en antigüedad son los instituidos en: Ermita de San Blas (Después, S. Gil), parroquias de 
ejemplo, en Santa Catalina, formaba una congregación con una gran autonomía de la hermandad del Rosario, lo mismo ocurría en la hermandad de los Negritos, en el compás de la Laguna en donde se erigió una congregación totalmente autónoma... ${ }^{29}$.

Incluso los niños, a imitación de sus mayores, fueron capaces de organizar algunos Rosarios, como el que promovieron en 1735 en el convento de San Alberto en torno a una imagen de la Virgen del Carmen, que culminó en la creación de una congregación ${ }^{30}$ Otros más espontáneos y puntuales fueron los de los alumnos del Colegio de Mareantes.. ${ }^{31}$

\section{e) La importancia del barrio}

Se fue creando una auténtica geografía rosariana. Cada rosario tenía su propia "feligresía», es decir, su ámbito de influencia entre el vecindario ya que era éste quien sostenía con sus limosnas el sostenimiento de la procesión diaria. Por esta razón, se creaban unas fronteras no escritas, determinadas calles por las que normalmente transitaba, estaciones ordinarias a donde acudía. Aunque la competencia existía y a veces generaba enfrentamientos serios, también se constata una relación de solidaridad y cortesía entre los Rosarios vecinos, frecuentando sus sedes en las estaciones, y así, el retablo o la iglesia por donde transitaba una procesión era profusamente engalanada, se encendían luces y los hermanos la recibian con faroles y el Simpecado, celebrándose todo un curioso ceremonial con el canto de la Salve y algunas coplas, encuentro de Simpecados, etc.

\footnotetext{
S. Bernardo, S. Lorenzo, Conventos de monjas de Santa Isabel, parroquia de Santa María la Blanca, ermita de la Virgen de los Dolores (S. Marcos), Parroquia de Santa Ana, ermita de San José, Capilla Cruz del Rodeo, Hospital de los Viejos, Colegio de S. Acasio, Hermandad de la Pastora de Santa Marina, Capilla de S. Andrés, de los Flamencos (era un rosario mixto de hombres, mujeres y niños), Convento de Clérigos Menores, Parroquias de S. Roque y Magdalena, Conventos de la Merced y el Pópulo, Colegio de Niñas Huérfanas, Monasterio de S. Benito y parroquias de S. Nicolás, S. Isidoro y S. Ildefonso, las tres últimas en 5 de octubre de 1738

29 En el caso de Santa Catalina, hay un dato en acta capitular de 12-11-1749. Cfr. Archivo de San Román, Fondos de $\mathrm{N}^{a} \mathrm{~S}^{a}$ Rosario de Santa Catalina, libro $1^{2}$ actas. Sobre el Rosario de la Hermandad de los Negritos, vid: Moreno NavarRo, Isidoro, La Antigua Hermandad de los negros de Sevilla: Etnicidad, poder y sociedad en 600 años de historia. Sevilla, Universidad, 1997. En el compás de la Laguna existía un Rosario de mujeres desde 1735, en un primer momento dependiente de otro de hombres con la misma advocación, pero luego se separaron y tomaron una casa en alquiler como capilla.
}

Vid. mi artículo cit. en nota 23.

3n Ibidem. Año 1735 (11). Estos niños consolidaron muy pronto el Rosario entre el vecindario, organizando dos procesiones: de prima y madrugada. En 1736 fueron aprobadas sus Reglas por el arzobispo Luis Salcedo.

31 ARANDA, Gabriel de, op. y págs. cits. 
Igualmente solían invitarse entres sí en ocasión de algún acontecimiento festivo de alguna de ellas.

El Rosario público se convierte asi en un signo de identidad de cada barrio o collación, un elemento de incipiente configuración social en torno a la religión, que se hace más patente en arrabales de indudable marginalidad, como el de los Humeros, donde, como en otros muchos casos, la sede de este Rosario es un humilde retablo callejero. El barrio se nos presenta como cuna y sede que hace nacer este Rosario y que vive a diario su progreso y consolidación desde su propio entorno físico y humano, sintiéndolo como un patrimonio propio y sobre todo como un medio familiar, cercano de encuentro con la Transcendencia que se hace tangible en la devoción a la Virgen, cuya imagen vive con ellos y los patrocina ${ }^{32}$.

\section{f) La hermandad como configuradora definitiva del instituto rosariano. Los sufragios y la labor asistencial}

La mayoría de ellos estaban ya constituidos en congregaciones (sin estatutos formalmente aprobados por la Autoridad Eclesiástica) o hermandades. La hermandad se convierte así, como ya he escrito en diversos artículos, en el ente que preserva y canoniza una devoción o práctica concreta surgida espontáneamente en el pueblo, una asociación peculiar y de honda tradición, que va a servir como medio de integrar en la Iglesia a diversos fenómenos de religiosidad, no coartando o limitando su espontaneidad, sino únicamente dotándolos de una necesaria estructura organizativa de gobierno y con una dimensión cultual y caritativa, dentro de los márgenes de una institución aprobada por la jerarquia, dotada de cierta y práctica autonomía y que el pueblo no deja de sentir como suya, pues es él quien marca el pulso de su vida. Un caso bien significativo es el del Rosario de los Humeros, que logró aunar a devotos y vecinos en la construcción de una capilla propia, que ayudó no poco a la pastoral de la parroquia de San Vicente en un arrabal distante y conflictivo. La religiosidad popular aparece como un signo de comunión eclesial, aunque "per se" ha nacido y se desarrolla con un indudable sentido de marginalidad. De hecho, nunca faltaron las disensiones cofrades-clero.

32 Sobre la vinculación de estos rosarios con los barrios, vid. mi artículo: "La iniciativa popular en la conformación de la religiosidad cotidiana: Hermandades y vecindad en la Sevilla del $\mathrm{Ba}$ rroco y la llustración", en Actas del XI Congreso de Profesores-Investigadores de "Hespérides". Palos de la Frontera, 1992., págs. 253-268. 
Lo que sí queda ya patente es que desde que comenzó el fenómeno de los Rosarios, se debilitó hasta desaparecer todo tipo de jurisdicción exclusiva dominica sobre la devoción y, aunque hubo diversos pleitos, lo cierto es que las Cofradías del Rosario coexistieron con las nuevas hermandades diocesanas, dependientes de la Mitra y sin más vinculación con las cofradías que la que emanaban de la participación en sus gracias e indulgencias concedidas a aquellas por los papas, previa solicitud e inscripción de los cofrades de cada hermandad en los libros de la Primitiva Cofradía del Rosario del convento de San Pablo, trámite que debía verficarse anualmente. Fueron muchas las hermandades y congregaciones que así lo hicieron. Incluso hubo algunas como la erigida en la parroquia de San Marcos que mantenía estrecha relación con la comunidad dominica, concretamente la del convento de Regina, adonde acudía cada sábado con su Rosario a verificar estación. Significativo es asimismo el hecho de que, cuando en ocasión de la bendición de su Simpecado, el Rosario de la Virgen de la Antigua de las Gradas convocó a todos los de la ciudad, eligió como padrinos a los del Consuelo del convento de San Pablo y dependiente de la Orden y al del Colegio de Santo Tomás ${ }^{33}$.

A mi parecer, los propios frailes de Santo Domingo aceptaron de buen grado esta situación. Bien significativo es el caso de esta Congregación del Rosario de Nuestra Señora del Consuelo, dedicada al ejercicio público rosariano, que dependía del convento de San Pablo, pero a la vez tenía todas las características de una hermandad diocesana. Gozaba de plena autonomía en el desarrollo de su instituto e incluso se potenciaban sus actividades por los frailes, que valoraban su arraigo popular, no pensando en ningún momento en anexionarla a la Cofradía. Una excepción la constituyó la comunidad dominica de San Jacinto, que entabló un enconado pleito con la parroquia de Santa Ana y la hermandad rosariana alli establecida, que provocó muchas tensiones entre ambos cleros. Los frailes se oponían a que una corporación ostentara el título de Rosario sin licencia

33 Fue un gran acontecimiento en la ciudad. Tuvo efecto 22 de junio de 1738 . A expensas del arzobispo, se había confeccionado un Simpecado para el Rosario que salía al alba de las Gradas (Fue uno de los primeros rosarios tanto de Prima (27-8-1690) como Madrugada (7-121690 ), bajo el lienzo del Cristo con la Cruz a cuestas. Había otra congregación rosariana en una capilla bajo el retablo de la Concepción de la Virgen y que se intitulaba de la Asunción. Fueron convocados todos los rosarios públicos de la ciudad. Se conserva una relación de esta efemérides inserta en un Libro de Acuerdos de la Congregación de $\mathrm{N}^{\mathrm{a}} \mathrm{S}^{\mathrm{a}}$ del Consuelo del convento de San Pablo. (Cfr. Archivo Palacio Arzobispal (A.P.A), Hermandades, leg. 12, fols. 13-18 vto.).Sobre esta interesante congregación, vid. mi artículo “Hacia una pretendida aproximación de la religión popular en la Sevilla del Barroco. La Congregación del Rosario de Nuestra Señora del Consuelo en el siglo XVIII», Revista de Humanidades, núm.7 (1997). Centro Asociado de la UNED. Sevilla, págs. 193-204. 
de la Orden. Aunque hubo una primera sentencia favorable a la hermandad, finalmente el Nuncio falló en 1747 favor del Convento y hubo que variar la advocación del Rosario por la de Madre de Dios. La cuestión de fondo no era sólo jurídica, sino de fijación de los límites pastorales (ya hemos hablado de la geografía rosariana) y sus muchas implicaciones económicas derivadas de las limosnas ${ }^{34}$.

Al referirnos a las hermandades rosarianas que, a partir de finales del siglo XVII, están establecidas en Sevilla, hay que distinguir:

1) Cofradias del Rosario: institución dependiente de la Orden de Predicadores y erigida en sus conventos o en otros templos con licencia del Maestro General. Su instituto fundamental consiste en el rezo del Santo Rosario y el culto a la Virgen del Rosario a través de diversas festividades, especialmente la Función Solemne del primer domingo de octubre con Procesión por las calles de la feligresía o la Función de las Rosas en mayo. Realiza mensualmente procesiones claustrales con la imagen.

Cuenta con numerosas gracias y privilegios concedidos por los papas.

2) Hermandades de Nuestra Señora del Rosario: corporación dependiente del Ordinario diocesano, dedicada al ejercicio del Rosario público y al culto anual a la imagen titular, a quien dedica una Función. En su instituto es una dimensión muy importante el sufragio por los cofrades difuntos.

3) Hermandades rosarianas con otra advocación: Es el caso de hermandades cuyo titular no es la Virgen del Rosario, pero su instituto primordial, o al menos importante, consiste en la salida del Rosario público, aunque desarrollan un culto diario a su imagen titular y una Función en su festividad. Normalmente suelen tener establecida una diputación del Rosario, con una clara autonomía respecto a la administración general de la hermandad.

4) Congregaciones rosarianas o de la Virgen del Rosario: asociación espontánea de vecinos y devotos dedicada a la organización y fomento del Rosario público, pero que no se haya constituida formalmente como Hermandad, al no tener presentadas Reglas para su aprobación por la Autoridad Eclesiástica.

5) Hermandades rosarianas de culto no procesional: son aquellas que tienen como titular a la Virgen del Rosario, le celebran sus cultos cotidianos

34 Matute Gaviria, Justino, Aparato para escribir la historia de Triana y su iglesia parroquial. Sevilla, 1912. Hay reedición fascimil de 1977, pág. 70. En las primitivas Reglas de 1693 se hace mención a este pleito y a la decisión de no apelar a Roma por los gastos que ello conllevaría. 
y anuales, pero no tienen establecido un Rosario público, aunque muchas procesiones solían acudir a hacer estación a sus sedes. Son los casos, por ejemplo, de las hermandades de la Costanilla del Salvador o de la Cestería. La constitución de estos Rosarios en congregaciones o hermandades hace que su campo de acción se extienda hacia aspectos cultuales y de asistencia. En efecto, el instituto primitivo se limitaba casi exclusivamente al uso público por las calles, pero poco a poco se va generando una devoción a la imagen titular de este Rosario y que figura representada en el lienzo del Simpecado, pero muchas veces con una iconografía de serie, que ahora se individualiza y define e incluso se sustituye por una talla de madera, a la que se dedica una Función anual. Al mismo tiempo, el Rosario desarrolla una labor asistencial entre sus cofrades y vecinos, centrado sobre todo en el sufragio por los difuntos, incluyendo aparato mortuorio (El Cristo de la Paz, titular de la hermandad de los Humeros, servía para este uso, aparte de presidir los via crucis),vela, acompañamiento del cadáver e, incluso, su enterramiento. Por ejemplo, en las Reglas de la Hermandad de la Pura y Limpia del Postigo se expresa que su instituto es «[...] aumentar la devoción del Santísimo Rosario, enterrar a los muertos y hacer el bien por las benditas ánimas, razón por la cual todos los días del año, al toque de oraciones, ha de salir el Rosario haciendo las acostumbradas estaciones [...]". Una institución tan arraigada en las gentes, imbuidas de ese clima de preocupación por la salvación eterna derivado de la Peste y las Misiones, no podía menos que implicarse en un compromiso de esta índole. En cada procesión del Rosario los vivos se unen a los difuntos en unas honras en las que se siente tan profundamente la cercanía de Dios y la mediación de la Virgen ${ }^{35}$. En no pocas ocasiones, el Rosario se consolida en congregación permanente debido a esta inquietud de asistencia post mortem. En una hermandad humilde como la ya citada del Rosario de la Resolana, se establece la dimensión de sufragio del Rosario público:

«Para sufragio de las almas de nuestros hermanos defuntos y utilidad espiritual con el recuerdo de la muerte establezemos que luego que aiga notizia que a fallezido algún hermano, el escribano lo publicará en la capilla antes de salir el Rosario para que todos lo sepan y procuren en los nueve días siguientes hazer por sus almas sufragios que pudieren, advirtiéndolos que con la medida que midiéramos emos de ser medidos; y en la misma

35 Cfr. Archivo Palacio Arzobispal (A.P.A.), Hermandades, leg. 30. Sobre esta labor asistencial de la Hermandad, vid. mi artículo: «Aproximación al estudio de los esquemas de religiosidad sevillana que conoció fray Diego José de Cádiz", en Estudios Franciscanos 96. Homenaje a fray Diego José de Cádiz, núm. 414 (1995), págs. 365-387. 
noche irá el Rosario temprano a la casa mortuoria y luego que llegue cantará un responso y si hubiere comvite de otro Rosario no permanescerá allí el nuestro asta rezevir y despedirlos todos y luego cantará otro responso para bolverse, pero no se executará esto en caso que la casa mortuoria no reziva Rosarios o sea tan lejos que se pueda como tal hazer la estación porque entonses se cantará el Responso en la capilla a la buelta del Rosario. $Y$ asimismo el hermano mayor dispondrá se lleve a la casa mortuoria dose sirios y el paño de entierros que adelante se hiziere para que sirva a nuestro hermano y mandará desir seis misas rezadas" $[\ldots]^{36}$.

Para acceder a estos sufragios era necesario que el cofrade estuviera al corriente de sus cuotas. Hay que tener en cuenta que en estas corporaciones la economía era de auténtica subsistencia. No obstante, las disposiciones varian según la hermandad, pues otras contemplaban la obligación de estos sufragios a los cofrades pobres e incluso a vecinos sin recursos. También, según la Hermandad, el sufragio se extendía o no al cónyuge e hijos del cofrade. La asistencia podía dirigirse también a los cofrades enfermos, a los que el Rosario iba a su domicilio para visitarle y darle ánimos. Se conservan unas coplas del Rosario público de la Hermandad de Nuestra Señora de las Maravillas de finales del XVIII o principios del XIX. Reproducimos algunas estrofas del coro ${ }^{37}$ :

\author{
"Dad la salud a este enfermo, \\ Virgen de las Maravillas. \\ Eres Madre de los Afligidos, \\ eres Quien sus penas alivias, \\ hallando firme consuelo \\ en las mismas fatigas \\ Dad la salud a este enfermo, \\ Virgen de las Maravillas. \\ En el destierro del mundo \\ todo es pena y desdicha. \\ Mas con tu auxilio, Señora, \\ todo es gozo y alegría.."
}

\title{
g) La decadencia de finales de siglo. La ruptura de la cristiandad barroca
}

Pero a pesar del gran número de Rosarios y de la complejidad a la que habian llegado en sus cortejos, estas procesiones comenzaron a

\footnotetext{
36 Vid. nota 13

37 Cfr. Archivo Palacio Arzobispal (A.P.A.), Expediente de aprobación de Reglas. 1805, Hermandades, leg. 17
} 
declinar en la segunda mitad del XVill. Se había perdido la primitiva espontaneidad y las limosnas de los vecinos no bastaban para sufragar los gastos. Algo fallaba cuando algunos de estos Rosarios tenían que solicitar la ayuda de "enganchadores" que antes de la salida iban por las calles, presionando a los vecinos para que participaran en la procesión. Había comitivas muy ricas, con notable aparato musical y prácticamente vacías. Los Rosarios parecían haberse convertido en formas huecas de una religiosidad que no existía con la fuerza y sinceridad de épocas pasadas. Se resquebrajaba la cristiandad barroca.

En esta época hay que hacer mención a unas curiosas diatribas entre dos eclesiáticos sobre la validez o no de los Rosarios públicos. Uno de ellos realiza duras críticas sobre la degradación a que se había llegado y a los incidentes que se producian cuando varios Rosarios se encontraban en una calle: $[\ldots]$

"Como si fuera un encuentro mundano, se evacuan primero sus políticas $y$, convenidos cual ha de tomar el mejor lugar, hasta las imágenes hacen su cumplido despidiéndose con muchas cabezadas los Simpecados... Y, con todo, no es lo peor. No hace mucho tiempo... acudir al juez para que decidiese cual de los dos Rosarios había de tener lugar en el paso porque, no estando los concurrentes de humor para observar estas políticas en sus encuentros, se expusieron más de una vez a que decidieran las manos sus preferencias $[\ldots]$ ".. 38 .

Las medidas del gobierno ilustrado fueron poco a poco abriendo un horizonte evidente en la mentalidad del pueblo: la religión no era ya la única instancia posible para entender la realidad y el sentido de lo que ocurre. No se podía seguir inmersos en unos esquemas contrarreformistas, y se origina una crisis indudable en la religiosidad popular, de la que un buen índice son los Rosarios. Poco a poco se disminuyen las procesiones diarias, sobre todo las de prima noche mientras que las de madrugada tienden a salir los festivos y con su denominación ya de la aurora, que poco a poco va cobrando una nueva fuerza durante toda la centuria decimonónica, especialmente en su segunda mitad y perdurará en el tiempo hasta las primeras décadas del siglo actual.

Van desapareciendo los retablos callejeros desde la mitad del siglo $x I x$ por mor de las reformas urbanísticas que se van haciendo necesarias en Se-

38 La postura crítica la representaba Francisco de P. Baquero, cura más antiguo del Sagrario. Cfr. Carta apologética. Respuesta al señor D. José López Herreros, del Consejo de S.M. [...] con el motivo de volver a dicho señor la tercera parte de la colección de ldeas elementales de educación, Sevilla, 1784. 
villa. Es otro signo más de la decadencia de esa religiosidad popular barroca cotidiana, dinámica y espontánea. Las devociones tienden a volver a los ámbitos templarios y de ellos son bien conscientes las propias congregaciones y hermandades rosarianas con retablos, por ejemplo la de la Virgen de Europa, cuyo retablo se traslada su retablo a San Martín, ciertamente por la inminencia de la demolición del sitio donde se hallaba, pero con la convicción de sus cofrades de que ya no tenía sentido permanecer allí.

El instituto rosariano va siendo sustituido por la procesión anual de la imagen titular de la hermandad o congregación, que conserva los elementos del Rosario público y, de hecho, en los primeros momentos mantiene su condición de tal con sus insignias de Gala. Al limitarse la cotidianidad, se da mayor importancia al culto interno y sólo queda la Procesión como testimonio de lo que fue en muchos casos el origen de la Hermandad.

Pero todo esto, pertenece ya a una época distinta del Barroco, eje central de este artículo. 